\title{
ACCURACY OF ENDOMETRIAL THICKNESS MEASUREMENT IN DIAGNOSIS OF ENDOMETRIAL CARCINOMA
}

Anusha Lingaiah Pujar ${ }^{1}$, Rani Ann Joseph ${ }^{2}$

${ }^{1}$ Senior Resident, Department of Radiodiagnosis, District Hospital, Bellary, Karnataka.

${ }^{2}$ Senior Resident, Department of Radiodiagnosis, Government Medical College, Thrissur.

\section{ABSTRACT}

\section{BACKGROUND}

Aim is to study the accuracy of endometrial thickness measurement in diagnosis of endometrial carcinoma using histopathological results as the gold standard.

\section{MATERIALS AND METHODS}

120 patients (with postmenopausal bleeding) referred to the Department of Radiodiagnosis were included in the study after applying inclusion and exclusion criteria. 2-D ultrasound was performed and endometrial thickness, echogenicity, were recorded on transvaginal ultrasonography. Cut-off was obtained after drawing ROC for endometrial thickness in differentiating benign and malignant pathology.

\section{RESULTS}

Using endometrial thickness as the diagnostic test, present study shows a sensitivity of $100 \%$ and specificity of $61.7 \%$ ( $<<0.0001$ ) for differentiating benign and malignant endometrial lesions.

\section{CONCLUSION}

Endometrial thickness can be effectively used to differentiate between endometrial carcinoma and benign lesions.

\section{KEYWORDS}

Endometrial Thickness, Echogenicity, Endometrial Carcinoma, Benign and Malignant Endometrium, Postmenopausal Bleeding.

HOW TO CITE THIS ARTICLE: Pujar AL, Joseph RA. Accuracy of endometrial thickness measurement in diagnosis of endometrial carcinoma. J. Evolution Med. Dent. Sci. 2017;6(30):2436-2441, DOI: 10.14260/Jemds/2017/526

\section{BACKGROUND}

Postmenopausal bleeding can be worrisome as sometimes it can be the first sign of endometrial carcinoma. Postmenopausal bleeding has been defined as vaginal bleeding occurring at least 6 months after complete cessation of periods in women not taking hormonal replacement therapy (HRT), or non-cyclic vaginal bleeding occurring in postmenopausal women who are receiving HRT. ${ }^{1}$

The common benign causes include atrophic endometrium, endometrial hyperplasia, endometrial polyp and malignant causes include endometrial carcinoma, cervical cancer and uterine leiomyosarcoma. ${ }^{2}$ The most common cause of postmenopausal bleeding is reported to be atrophic endometrium. ${ }^{3}$ However, recent studies indicate that leiomyomata and polyps are much more common than has been generally believed. ${ }^{4}$

A diagnosis of endometrial carcinoma should be considered in all women presenting with postmenopausal bleeding. ${ }^{2}$ Postmenopausal bleeding is the initial symptom in most of the of patients with endometrial carcinoma. 5 Early diagnosis and treatment are important because the prognosis is generally good, the five-year survival rate for endometrial

Financial or Other, Competing Interest: None.

Submission 01-03-2017, Peer Review 30-03-2017,

Acceptance 05-04-2017, Published 13-04-2017.

Corresponding Author:

Dr. Anusha Lingaiah Pujar,

Plot No. 25, BC Mallaiah Compound,

Jayanagar,

Ballari.

E-mail: anushapujar7@gmail.com

DOI: $10.14260 /$ jemds $/ 2017 / 526$ adenocarcinoma following appropriate treatment is $80 \%{ }^{6}$

Unfortunately, endometrium is not as accessible as cervix for screening tests. Dilation and curettage has been considered the gold standard for the diagnosis of endometrial carcinoma historically.

Imaging modalities like ultrasound have been used to differentiate between benign and malignant endometrial pathology.

Endometrial thickness has been reported to be a better predictor of endometrial pathology than Doppler indices. ${ }^{6}$

The present study was carried out to assess the accuracy of measurement of endometrial thickness in the diagnosis of endometrial carcinoma in Indian women presenting with postmenopausal bleeding while taking histopathological findings as the gold standard.

\section{MATERIALS AND METHODS}

This cross-sectional study was conducted in Department of Radiodiagnosis, Sree Avittom Thirunal Hospital, Thiruvananthapuram for eighteen months from May 2014 to October 2015. All patients above 50 years of age having history of postmenopausal bleeding, who have been referred to the Radiology Department of, Sree Avittom Thirunal Hospital, Government medical college, Thiruvananthapuram, Kerala, by consulting gynaecologists.

All patients with postmenopausal bleeding were included in the study.

Patients not willing to participate in the study, asymptomatic patients, perimenopausal and premenopausal patients, patients with fibroid uterus, patients with endometrial polyps, patients with endometrial cavitary fluid were excluded from the study. 
Study variables included are endometrial thickness, Endometrial Echogenicity and Endomyometrial junction.

Name, age and relevant details of the patient were recorded on a proforma. Patients were informed that data collected would be used in a study and that issues related to confidentiality and anonymity would be taken due care of.

After taking informed consent, Real-time ultrasonography was done with Phillips IU-22 ultrasound machine equipped with a $5 \mathrm{MHz}$ vaginal transducer. The vaginal probe covered with a coupling gel, inserted into a condom, coated with gel was inserted into the vaginal fornix, with the subject in the lithotomy position. With the uterus imaged in the longitudinal plane, endometrial thickness were measured as from echogenic border to echogenic border across the endometrial cavity on midline sagittal image.

Endometrial biopsy of these patients was carried out in the Gynaecology Department and sent to the Pathology Department of the Government Medical College Hospital, Thiruvananthapuram and was recorded almost after 1 week.

\section{RESULTS}

Ultrasonography was done for the patients with postmenopausal bleeding and the results were tabulated. Following findings were observed.

\section{Age Distribution of Patients}

\begin{tabular}{|c|c|c|c|c|}
\hline $\begin{array}{c}\text { Age } \\
\text { (years) }\end{array}$ & Benign & & Malignant & \\
\hline & $\begin{array}{c}\text { No. of } \\
\text { Patients }\end{array}$ & $\%$ & $\begin{array}{c}\text { No. of } \\
\text { Patients }\end{array}$ & $\%$ \\
\hline $51-55$ & 24 & 20 & 12 & 10 \\
\hline $56-60$ & 28 & 23.2 & 13 & 10.7 \\
\hline $61-65$ & 13 & 10.8 & 7 & 5.8 \\
\hline $66-70$ & 8 & 6.6 & 2 & 1.6 \\
\hline$>70$ & 8 & 6.6 & 5 & 4.1 \\
\hline Total & 81 & 67.5 & 39 & 32.5 \\
\hline
\end{tabular}

120 patients were imaged in total. 81 patients $(67.5 \%$ of the study population) had benign aetiology and 39 patients (32.5\% of the study population) had malignancy. Among the 39 patients, majority i.e., 10.7\% come under age group 61-65. The oldest patient was aged 75 years.

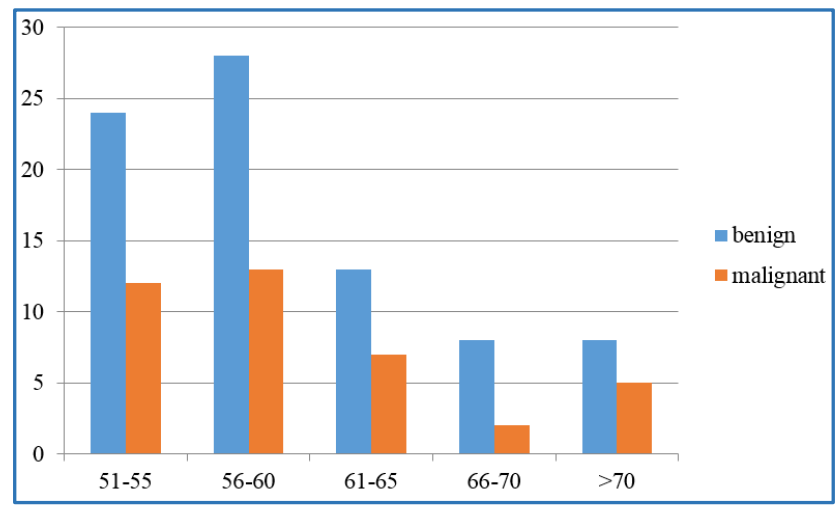

Image 1. Bar Diagram Showing Distribution of Benign and Malignant Cases According to Age

\section{HPR Distribution}

Among the malignant histopathological results, endometrioid type of adenocarcinoma constituted $76.93 \%$, papillary serous adenocarcinoma was $15.3 \%$ and adenocarcinoma with squamous differentiation was $7.7 \%$.

\begin{tabular}{|c|c|c|}
\hline Subtype & Frequency & \% \\
\hline Endometrioid & 30 & $76.93 \%$ \\
\hline Papillary serous adenocarcinoma & 6 & $15.30 \%$ \\
\hline $\begin{array}{c}\text { Adenocarcinoma with } \\
\text { squamous differentiation }\end{array}$ & 3 & $7.7 \%$ \\
\hline \multicolumn{2}{|c|}{ Table 2. Frequency Distribution of } \\
Histopathological Findings in Malignancy \\
\hline
\end{tabular}

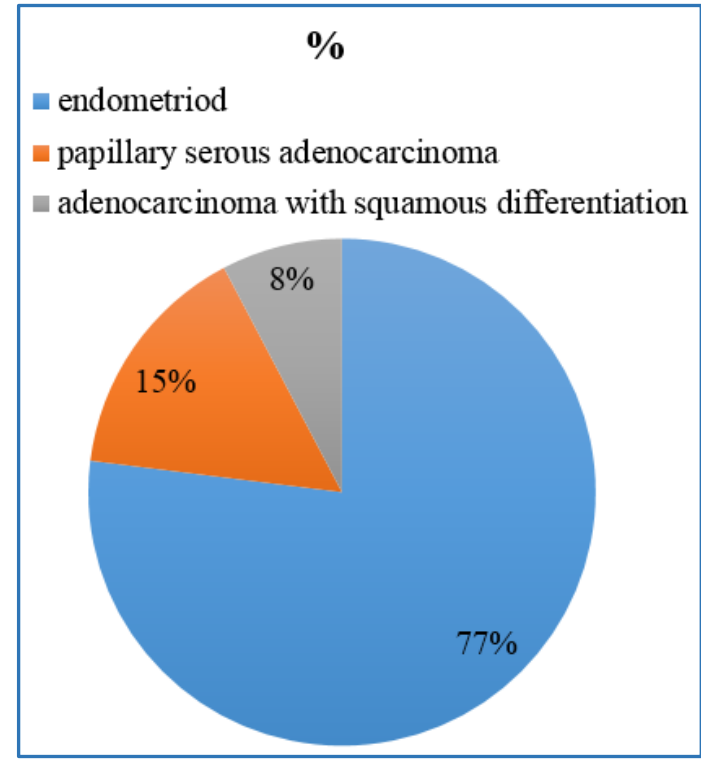

Image 2. Pie Chart Showing Distribution of Histopathological Findings in Malignancy

Out of the 81 benign patients, 68 patients had atrophic endometrium, 9 patients had hyperplasia, and 4 patients had proliferative type of endometrium.

\begin{tabular}{|c|c|c|}
\hline & Frequency & $\mathbf{\%}$ \\
\hline Atrophic & 68 & $84 \%$ \\
\hline Hyperplasia & 9 & $11 \%$ \\
\hline Proliferative & 4 & $5 \%$ \\
\hline \multicolumn{2}{|c|}{ Table 3. Frequency Distribution of } \\
Histopathological Findings in Benign Cases \\
\hline
\end{tabular}

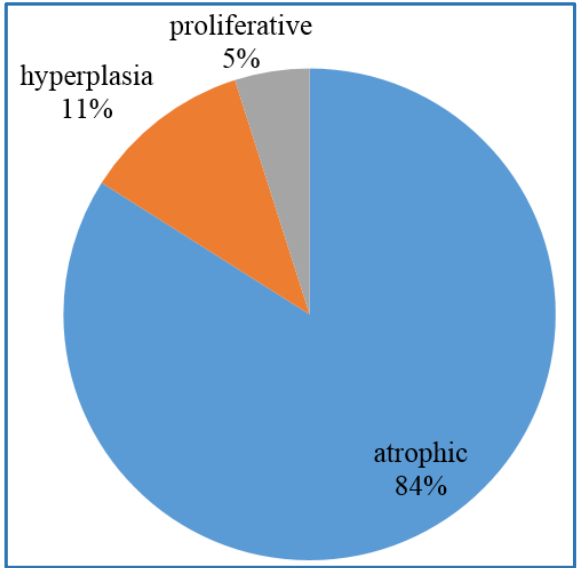

Image 3. Pie Chart Showing Frequency Distribution of HPR Findings in Benign Patients 


\section{Echogenicity of Endometrium}

Among the 120 patients, the endometrium appeared heterogeneous in 31 patients, out of which 28 patients had malignancy and 3 patients had benign aetiology. Out of the 89 patients with homogeneous appearing endometrium, 78 patients had benign aetiology and 11 patients had malignancy.

The sensitivity of the test was $71.7 \%$ and specificity was $96.3 \%$ with positive predictive value of $90.32 \%$ and negative predictive value of $87.6 \%$ with diagnostic accuracy of $88.3 \%$.

\begin{tabular}{|c|c|c|c|}
\hline Echogenicity & Malignant & Benign & Total \\
\hline Heterogeneous & 28 & 3 & 31 \\
\hline Homogeneous & 11 & 78 & 89 \\
\hline Total & 39 & 81 & \\
\hline \multicolumn{4}{|c|}{$\begin{array}{l}\text { Table 4. Frequency Distribution of Patients According to } \\
\text { Echogenicity of the Endometrium }\end{array}$} \\
\hline
\end{tabular}

\begin{tabular}{|c|c|}
\hline Sensitivity & $71.79 \%$ \\
\hline Specificity & $96.30 \%$ \\
\hline AUC & 0.84 \\
\hline Positive Likelihood Ratio & 19.38 \\
\hline Negative Likelihood Ratio & 0.29 \\
\hline Disease prevalence & $32.50 \%$ \\
\hline Positive Predictive Value & $90.32 \%$ \\
\hline Negative Predictive Value & $87.64 \%$ \\
\hline Table 5. Statistical Parameters of Echogenicity \\
\hline
\end{tabular}

\begin{tabular}{|c|c|}
\hline \multicolumn{2}{|c|}{ Malignancy } \\
\hline Proportion (\%) & 71.7 \\
\hline Number of Cases & 39 \\
\hline \multicolumn{2}{|c|}{ Benign } \\
\hline Proportion (\%) & 3.7 \\
\hline Number of Cases & 81 \\
\hline \multicolumn{2}{|c|}{$\begin{array}{l}\text { Table 6. Comparison of Proportions of Patients } \\
\text { with Heterogeneous Endometrium in } \\
\text { Benign and Malignant Subgroups }\end{array}$} \\
\hline Difference & $68.00 \%$ \\
\hline Chi-squared & 60.084 \\
\hline Significance level & $\mathrm{P}<0.0001$ \\
\hline
\end{tabular}

Comparison of proportions show a p value of $<0.0001$ which implies that the difference is statically significant and the presence of heterogeneous endometrium can reliably used as an indicator of carcinoma endometrium.

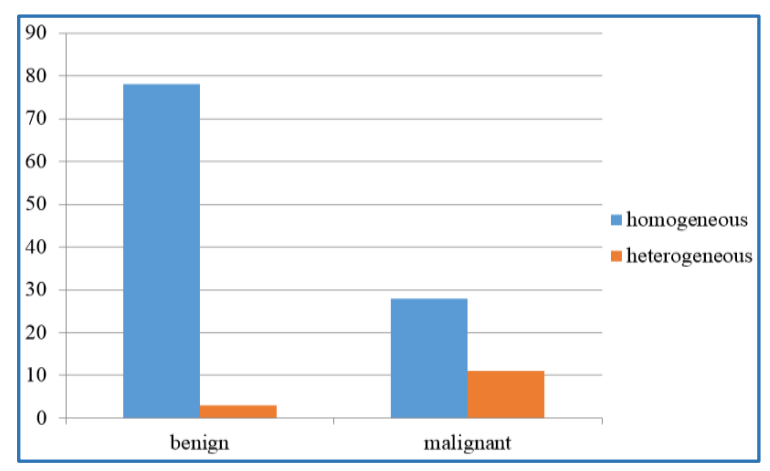

Image 4. Bar Diagram Showing Frequency Distribution of Echogenicity in Benign and Malignant Cases

\section{Endometrial Thickness}

B. Randelzhofer et al derived a cut-off of $5 \mathrm{~mm}$ for differentiating benign and malignant disease. With this cut- off, $2 \times 2$ Table was constructed to assess the diagnostic power of endometrial thickness with literature cut-off value.

\begin{tabular}{|c|c|c|c|}
\hline Endometrial Thickness & Malignant & Benign & \\
\hline$>5 \mathrm{~mm}$ & 39 & 31 & 70 \\
\hline \multirow[t]{2}{*}{$<5 \mathrm{~mm}$} & 0 & 50 & 50 \\
\hline & 39 & 81 & \\
\hline $\begin{array}{r}\text { Table 7. } 2 \times 2 \text { Table in As } \\
\text { Endometrial Thick } \\
\text { Cut-off Value (B. }\end{array}$ & $\begin{array}{l}\text { ng Diagnost } \\
\text { using Literc } \\
\text { delzhofer et }\end{array}$ & $\begin{array}{l}\text { Power } \\
\text { ure } \\
\text { l) }\end{array}$ & \\
\hline
\end{tabular}

The calculated parameters are as follows:

\begin{tabular}{|c|c|}
\hline Sensitivity & $100.00 \%$ \\
\hline Specificity & $61.73 \%$ \\
\hline AUC & 0.81 \\
\hline Positive Likelihood Ratio & 2.61 \\
\hline Negative Likelihood Ratio & 0.00 \\
\hline Disease prevalence & $32.50 \%$ \\
\hline Positive Predictive Value & $55.71 \%$ \\
\hline Negative Predictive Value & $100.00 \%$ \\
\hline \multicolumn{2}{|c|}{$\begin{array}{l}\text { Table 8. Statistical Parameters of Endometrial } \\
\text { Thickness Obtained using Literature } \\
\text { Cut-off Value (B. Randelzhofer et al) }\end{array}$} \\
\hline
\end{tabular}

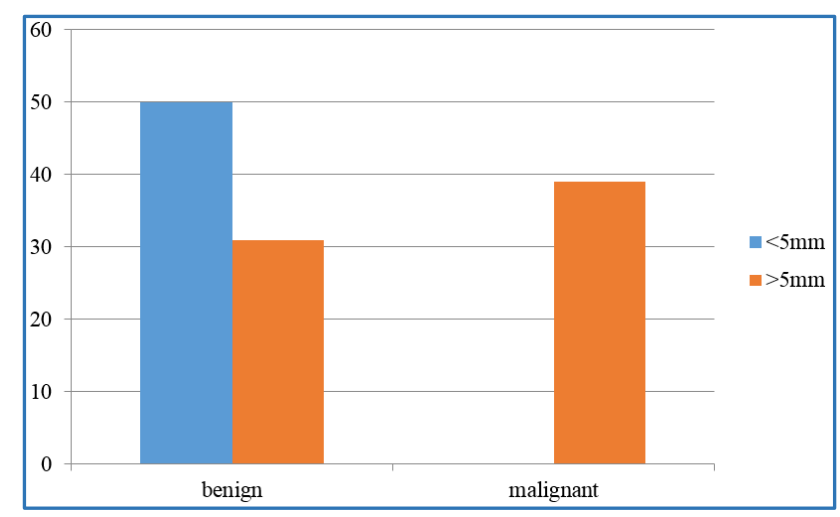

Image 5. Bar Diagram Showing Frequency Distribution of Endometrial Thickness

\begin{tabular}{|c|c|c|}
\hline Parameters & Benign & Malignant \\
\hline No. of cases & 81 & 39 \\
\hline Mean & 6.3 & 10.5 \\
\hline Median & 5 & 11 \\
\hline Standard deviation & 3.98 & 3.03 \\
\hline Maximum value & 15 & 15 \\
\hline Minimum value & 2 & 6 \\
\hline 95\% CI & $5.4-7.2$ & $9.5-11.5$ \\
\hline
\end{tabular}

Table 9. Statistical Analysis of Endometrial Thickness

\begin{tabular}{|c|c|}
\hline \multicolumn{2}{|c|}{ Malignant } \\
\hline Mean & 10.5 \\
\hline Standard deviation & 3.03 \\
\hline Number of cases & 39 \\
\hline \multicolumn{2}{|c|}{ Benign } \\
\hline Mean & 6.3 \\
\hline Results & 3.98 \\
\hline Nundard deviation & 42 \\
\hline \multicolumn{2}{|c|}{} \\
\hline Difference & -4.2 \\
\hline Standard error & 0.721 \\
\hline Test statistic t & -5.823 \\
\hline Significance level & $\mathrm{P}<0.0001$ \\
\hline
\end{tabular}

Table 10. Comparison of Means (t-test) of Endometrial Thickness in Benign and Malignant Subgroup 


\begin{tabular}{|c|c|c|c|c|c|c|}
\hline Criterion & Sensitivity & $95 \% \mathrm{CI}$ & Specificity & $95 \% \mathrm{CI}$ & $+\mathrm{LR}$ & -LR \\
\hline$\geq 2$ & 100.00 & $91.0-100.0$ & 0.00 & $0.0-4.5$ & 1.00 & \\
\hline$>5$ & 100.00 & $91.0-100.0$ & 61.73 & $50.3-72.3$ & 2.61 & 0.00 \\
\hline$>6$ & 87.18 & $72.6-95.7$ & 66.67 & $55.3-76.8$ & 2.62 & 0.19 \\
\hline$>7$ & 76.92 & $60.7-88.9$ & 69.14 & $57.9-78.9$ & 2.49 & 0.33 \\
\hline$>8$ & 69.23 & $52.4-83.0$ & 75.31 & $64.5-84.2$ & 2.80 & 0.41 \\
\hline$>9$ & 61.54 & $44.6-76.6$ & 75.31 & $64.5-84.2$ & 2.49 & 0.51 \\
\hline$>10$ & 53.85 & $37.2-69.9$ & 77.78 & $67.2-86.3$ & 2.42 & 0.59 \\
\hline$>11$ & 41.03 & $25.6-57.9$ & 82.72 & $72.7-90.2$ & 2.37 & 0.71 \\
\hline$>12$ & 30.77 & $17.0-47.6$ & 87.65 & $78.5-93.9$ & 2.49 & 0.79 \\
\hline$>13$ & 20.51 & $9.3-36.5$ & 91.36 & $83.0-96.5$ & 2.37 & 0.87 \\
\hline$>14$ & 12.82 & $4.3-27.4$ & 95.06 & $87.8-98.6$ & 2.60 & 0.92 \\
\hline$>15$ & 0.00 & $0.0-9.0$ & 100.00 & $95.5-100.0$ & & 1.00 \\
\hline
\end{tabular}

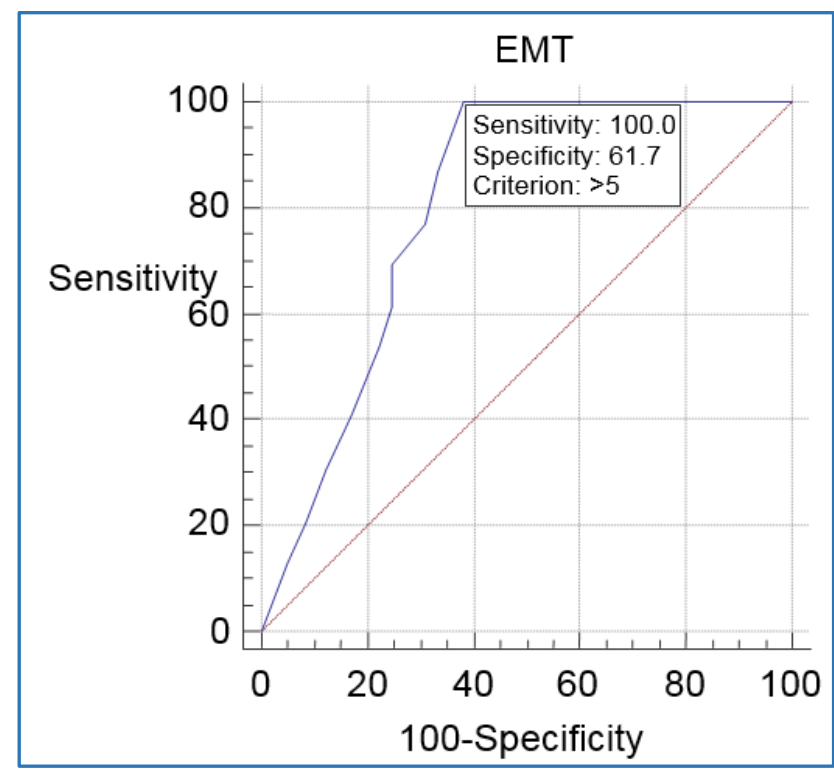

Image 6. Receiver Operator Characteristic Curve Analysis of Endometrial Thickness

From the graph, a cut-off value of $5 \mathrm{~mm}$ was derived. This cut-off has a sensitivity of $100 \%$ and specificity of $61.7 \%$.
Positive likelihood ratio with this cut-off is 2.61 and negative likelihood ratio is 0.0

\begin{tabular}{|c|c|c|c|}
\hline Endometrial Thickness & Malignant & Benign & \\
\hline$>5 \mathrm{~mm}$ & 39 & 31 & 70 \\
\hline$<5 \mathrm{~mm}$ & 0 & 50 & 50 \\
\hline & 39 & 81 & \\
\hline
\end{tabular}

Table 12. 2 × 2 Table in Assessing Diagnostic Power of Endometrial Thickness using Receiver operator Characteristic Curve Cut-off Value

\begin{tabular}{|c|c|}
\hline Area under the ROC curve (AUC) & 0.803 \\
\hline Standard Error & 0.0387 \\
\hline 95\% Confidence interval & 0.721 to 0.870 \\
\hline z statistic & 7.840 \\
\hline Significance level P (Area = 0.5) & $<0.0001$ \\
\hline Youden index J & 0.6173 \\
\hline Associated criterion & $>5$ \\
\hline Sensitivity & 100.00 \\
\hline Specificity & 61.73 \\
\hline Accuracy & $74.1 \%$ \\
\hline
\end{tabular}

Table 13. Parameters Obtained in Receiver Operator Characteristic Curve Analysis of Endometrial Thickness

\begin{tabular}{|c|c|c|c|c|c|c|c|c|}
\hline Study & Cut off $\mathbf{m m}$ & Sensitivity \% & Specificity \% & PPV \% & NPV \% & $+\mathrm{LR}$ & -LR & P value \\
\hline B. Randelzhofer & 5 & 97.9 & 33.2 & 38.1 & 97.4 & $-\cdots$ & $-\cdots$ & $<0.0001$ \\
\hline $\begin{array}{l}\text { Applying in } \\
\text { present study }\end{array}$ & 5 & 100 & 61.7 & 55.7 & 100 & 2.61 & 0.0 & $<0.0001$ \\
\hline $\begin{array}{l}\text { Applying the cut-off } \\
\text { derived from ROC }\end{array}$ & 5 & 100 & 61.7 & 55.7 & 100 & 2.61 & 0.0 & $<0.0001$ \\
\hline
\end{tabular}

Table 14. Comparison of Endometrial Thickness Obtained in the Study and the Literature

\section{Endomyometrial Junction}

The endomyometrial junction was indistinct in 22 of the 39 malignant cases and had a sensitivity of $56.4 \%$ and was distinct in 80 of the 81 benign cases with a specificity of $98.7 \%$.

\begin{tabular}{|c|c|c|c|}
\hline & Malignant & Benign & \\
\hline Indistinct & 22 & 1 & 23 \\
\hline Distinct & 17 & 80 & 97 \\
\hline & 39 & $\mathbf{8 1}$ & \\
\hline Table 15. 2x2 Table Showing Distribution of Distinct \\
and Indistinct of Endomyometrial Junction \\
in Benign and Malignant Cases \\
\hline
\end{tabular}

\begin{tabular}{|c|c|}
\hline Sensitivity & $56.41 \%$ \\
\hline Specificity & $98.77 \%$ \\
\hline AUC & 0.78 \\
\hline Positive Likelihood Ratio & 45.69 \\
\hline Negative Likelihood Ratio & 0.44 \\
\hline Disease prevalence & $32.50 \%$ \\
\hline Positive Predictive Value & $95.65 \%$ \\
\hline Negative Predictive Value & $82.47 \%$ \\
\hline Accuracy & $85 \%$ \\
\hline \multicolumn{2}{|c|}{$\begin{array}{l}\text { Table 16. Statistical Parameters of Indistinct } \\
\text { Endomyometrial Junction }\end{array}$} \\
\hline
\end{tabular}




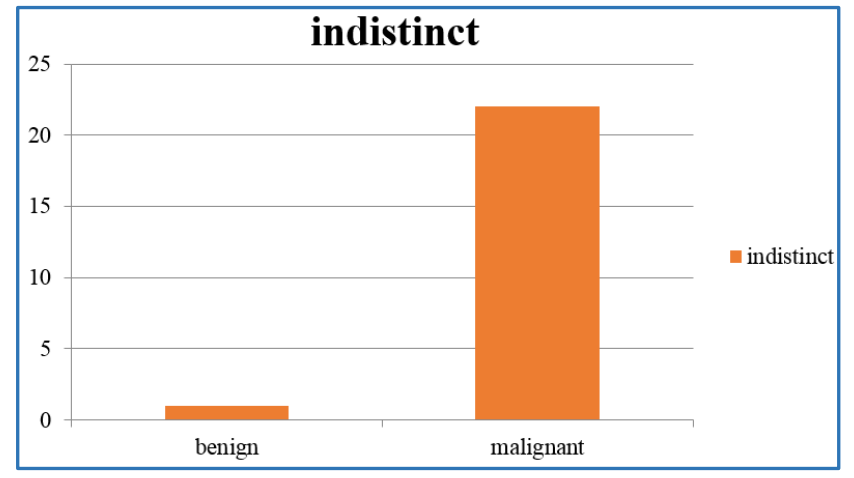

Image 7. Bar Diagram Showing Distribution of Indistinct Endomyometrial Junction in Benign and Malignant Cases

\begin{tabular}{|c|c|}
\hline \multicolumn{2}{|c|}{ Malignant } \\
\hline Proportion (\%) & 56 \\
\hline Number of Cases & 39 \\
\hline \multicolumn{2}{|c|}{ Benign } \\
\hline Proportion (\%) & 1.2 \\
\hline Number of Cases & 81 \\
\hline \multicolumn{2}{|c|}{ Results } \\
\hline Difference & $54.80 \%$ \\
\hline Chi-Squared & P < 0.0001 \\
\hline $\begin{array}{c}\text { Table 17. Comparison of Proportions of Patients with } \\
\text { Indistinct Endomyometrial Junction in } \\
\text { Benign and Malignant Subgroups }\end{array}$ \\
\hline
\end{tabular}

Comparison of proportions show a p value of $<0.0001$ which implies that the difference is statistically significant, and hence indistinct endomyometrial junction can be used reliably as an indicator in identifying patients with carcinoma endometrium.

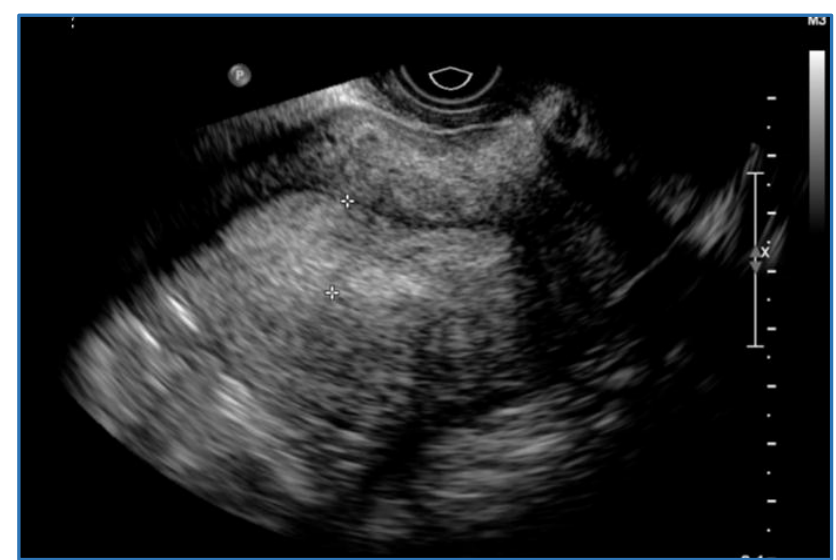

Figure 1. Thickened and Homogeneous Endometrium, with Distinct Endomyometrial Junction. HPR - Endometrial Hyperplasia

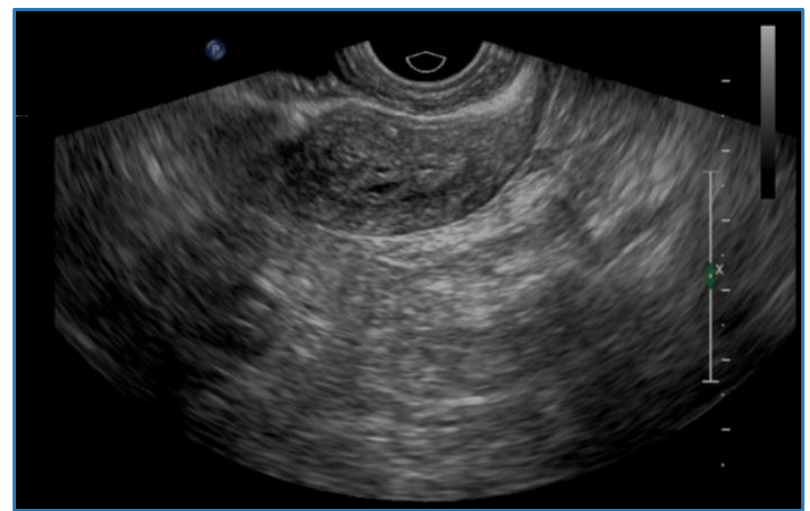

Figure 2. Thickened and Heterogeneous Endometrium, with Indistinct Endomyometrial Junction, Predominantly in the Anterior Aspect. HPR - Endometrial Carcinoma

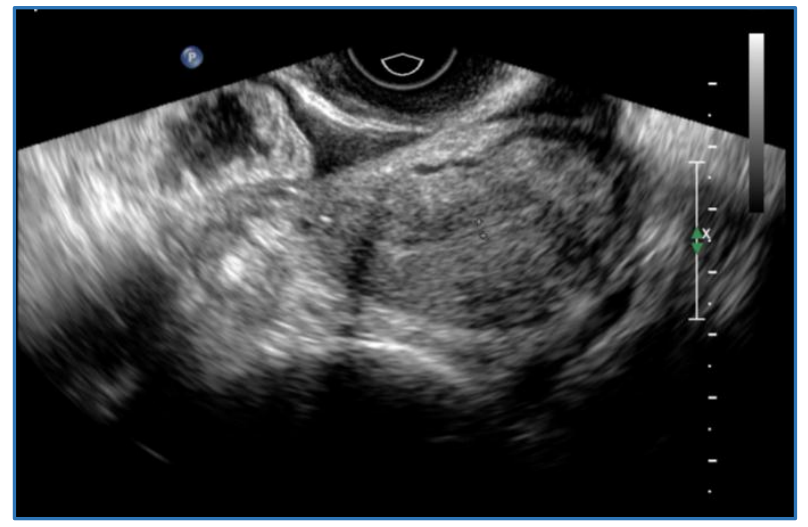

Figure 3. Thinned out Endometrium, with Distinct Endomyometrial Junction. HPR - Atrophic Endometrium

\section{DISCUSSION}

Age Distribution

Among the 120 patients studied, 39 patients proved to have malignancy and $30.7 \%$ belonged to age group $51-55,32.9 \%$ belonged to age group 56-60, $17.8 \%$ belonged to age group $61-65,4.9 \%$ to age group $66-70$ and $12.6 \%$ to age group $>70$. According to the study by Amant $\mathrm{F}$ et al, endometrial carcinoma had a peak in 7 th decade. ${ }^{7}$

\section{Histopathological Results}

$76.9 \%$ of the patients had endometrioid type of adenocarcinoma on HPR. Next common subtype being papillary serous adenocarcinoma. As given by Sala et al in a journal published in AJR, adenocarcinoma arise from uterine epithelium and constitute $90 \%$ of endometrial cancers.

Among the benign conditions, atrophic endometrium constituted $83.9 \%$ of the cases, $11.1 \%$ had hyperplasia, $4.9 \%$ had proliferative type of endometrium.

In the study by B Randelzhofer, endometrial atrophy was seen in $45.1 \%$, endometrial proliferation in $8.3 \%$, endometrial hyperplasia in $16.3 \%$, and endometrial polyps in $30 \% .^{8}$ 


\section{Echogenicity}

Among the 120 patients, the endometrium appeared heterogeneous in 31 patients, out of which 28 patients had malignancy and 3 patients had benign aetiology.

The sensitivity of the test was $71.7 \%$ and specificity was $96.3 \%$ with positive predictive value of $90.32 \%$ and negative predictive value of $87.6 \%$ with diagnostic accuracy of $88.3 \%$.

Study by Opolskiene et al concluded that heterogenous endometrial echogenicity was the single best ultrasound variable for predicting endometrial malignancy. ${ }^{9}$ The internal endometrial structure most suggestive of malignancy was subjectively perceived as being 'moth eaten'.

Comparison of proportions show a $p$ value of $<0.0001$ which implies that the difference between benign and malignant subgroups is significant.

\section{Endometrial Thickness}

Among the 120 patients, all the patients with endometrial carcinoma had endometrial thickness of $>5 \mathrm{~mm}$. When the cut off value is set for $5 \mathrm{~mm}$, the test proved to have a sensitivity of $100 \%$.

31 patients with benign aetiology also had endometrial thickness of $>5 \mathrm{~mm}$, which reduces the specificity to $61.7 \%$. Positive predictive value of the test was $55.7 \%$, negative predictive value $100 \%$ with diagnostic accuracy of $74.1 \%$.

Mean endometrial thickness was found to be $6.3 \pm 3.98$ $\mathrm{mm}$ in benign and $10.5 \pm 3.03 \mathrm{~mm}$ in malignancy ( $\mathrm{t}$ test, $\mathrm{p}<0.001$ ).

B. Randelzhofer et al derived a cut-off of $5 \mathrm{~mm}$ for differentiating benign and malignant disease which had a sensitivity of $97.9 \%$, specificity of $33.2 \%$, positive predictive value of $38.1 \%$ and negative predictive value of $97.4 \%{ }^{8}$

In another study conducted by Mahmoud El-Morsi AboulFotouha et al, taking an endometrial thickness of $5 \mathrm{~mm}$ as a cut off value for prediction of endometrial malignancy had $100 \%$ sensitivity, $51.9 \%$ specificity, $60.9 \%$ positive predictive value, $100 \%$ negative predictive value, and $48.7 \%$ diagnostic accuracy. ${ }^{10}$

\section{Endomyometrial Junction}

The endomyometrial junction was indistinct in 22 of the 39 malignant cases and had a sensitivity of $56.4 \%$ and was distinct in 80 of the 81 benign cases with a specificity of $98.7 \%$. Positive predictive value of the test was $95.6 \%$, negative predictive value $82.4 \%$ with diagnostic accuracy of $85 \%$.

Comparison of proportions show a p value of $<0.0001$ which implies that the difference between the benign and malignant subgroups is significant.

Myometrial invasion is depicted as irregularity of the endometrium - myometrium border and disruption of the subendometrial halo. According to Teefey SA et al, the accuracy of US in diagnosing the depth of invasion is approximately $73 \%$ to $93 \%$, but US is better for grade $2-3$ tumours and should not be used as the sole criterion for the decision to perform extensive surgery. ${ }^{11}$

The study by Opolskiene et al concluded that Irregular endometrial-myometrial border was also a sign of endometrial cancer. ${ }^{9}$

In the study conducted by B Randelzhofer et al, the sensitivity of indistinct endomyometrial border had a sensitivity of $73.7 \%$ and specificity of $87.7 \%{ }^{8}$

\section{Limitations of the Study}

1. Subjective inference of endometrial morphology.

2. Small sample size. Similar results should be reproduced in larger numbers and in a different population prior to being introduced in a clinical setting.

3. These results are applicable to examinations carried out using similar ultrasound system and transducer.

\section{CONCLUSION}

Endometrial thickness can be effectively used to differentiate between endometrial carcinoma and benign lesions. Thus, a conservative approach can be recommended for women with endometrial thickness of $<5 \mathrm{~mm}$ avoiding unnecessary dilation and curettage.

\section{ACKNOWLEDGEMENTS}

We are thankful to Department of Radiology, Government Medical College, Thiruvananthapuram for all the help in carrying out this study.

\section{REFERENCES}

[1] Malcolm MG. Southern California Permanente Medical Group's Abnormal Uterine Bleeding Working Group. Investigation of women with postmenopausal uterine bleeding: clinical practice recommendations. Permanente Journal 2014;18(1):55-70.

[2] Grube W, Ammon T, Killen MD. The role of ultrasound imaging in detecting endometrial cancer in postmenopausal women with vaginal bleeding. J Obstet Gynecol Neonatal Nurs 2011;40(5):632-7.

[3] Ghazi A, Jabbar S, Siddiqi N. Frequency of endometrial carcinoma in patients with postmenopausal bleeding. Pak J Surg 2005;21:41-4.

[4] Buchanan EM, Weinstein LC, Hillson C. Endometrial cancer. Am Fam Physician 2009;80(10):1075-80.

[5] Chen SS, Lee L. Retroperitoneal lymph node metastases in stage 1 carcinoma of the endometrium: correlation with risk factors. Gynecol Oncol 1983;16(3):319-25.

[6] Nalaboff KM, Pellerito JS, Ben-Levi E. Imaging the endometrium: disease and normal variants. RadioGraphics 2001;21(6).

[7] Amant F, Moerman P, Neven P, et al. Endometrial cancer. Lancet 2005;366(9484):491-505.

[8] Randelzhofer B, Prompeler HJ, Sauerbrei W et al. Value of sonomorphological criteria of the endometrium in women with postmenopausal bleeding: a multivariate analysis. Ultrasound Obstet Gynecol 2002;19(1):62-8.

[9] Opolskiene G, Sladkevicius P, Valentin L. Prediction of endometrial malignancy in women with postmenopausal bleeding and sonographic endometrial thickness $\geq 4.5 \mathrm{~mm}$. Ultrasound Obstet Gynecol 2011;37(2):232-40.

[10] AbdelMaboud NM, Elsaid HH. Role of transvaginal ultrasonography and colour Doppler in the evaluation of postmenopausal bleeding. Egyptian Journal of Radiology and Nuclear Medicine 2015;46(1):235-43.

[11] Teefey SA, Stahl JA, Middleton WD, et al. Local staging of endometrial carcinoma: comparison of transvaginal and intraoperative sonography and gross visual inspection. AJR Am J Roentgenol 1996;166(3):547-52. 